\title{
ANALISIS KARAKTERISTIK PARKIR DI SATUAN RUANG PARKIR PASAR LARANGAN SIDOARJO
}

\author{
Riyadlus Sholikhin $^{1}$, Sri Wiwoho Mudjanarko² \\ Teknik Sipil, Fakultas Teknik Sipil \\ Universitas Narotama, Surabaya, Indonesia \\ e-mail : ${ }^{2}$ sri.wiwoho@narotama.ac.id
}

Diterima: 18 Nopember 2017. Disetujui : 15 Desember 2017. Dipublikasikan : 18 Desember 2017

(C)2017 -TESJ Fakultas Teknik Universitas Maarif Hasyim Latif. Ini adalah artikel dengan akses terbuka di bawah lisensi CC BY 4.0 (https://creativecommons.org/licenses/by/4.0/)

\begin{abstract}
ABSTRAK
Perparkiran merupakan masalah yang sering dijumpai, apalagi di daerah yang mempunyai aktivitas tinggi seperti pasar, yang sering kali menimbulkan kemacetan di jalan. Salah satu hal yang perlu dilakukan untuk meminimalkan masalah tersebut yaitu dengan analisa perparkiran pada lahan tersebut. Berdasarkan pada latar belakang tersebut di atas, maka hal yang perlu dianalisa adalah karakteristik parkir yaitu dengan melakukan perhitungan dan analisa terhadap durasi parkir, akumulasi parkir, tingkat pergantian (parking turn over), volume parkir, kapasitas parkir, indeks parkir, okupansi. Berdasarkan hasil analisis diperoleh kesimpulan bahwa karakteristik parkir jenis sepeda motor di badan jalan pada hari libur 1.104 kendaraan dengan akumulasi tertinggi 133 kendaraan dan rata-rata durasi parkir 128,52 menit/kendaraan. Nilai turn over tertinggi 7,63 dan tingkat penggunaan parkir tertinggi 190,34\%. Jumlah petak parkir yang tersedia saat ini yaitu 150 petak parkir sehingga kapasitas ini tidak mampu menampung pengguna parkir saat jam puncak. Sementara untuk karakteristik parkir jenis mobil adalah volume parkir mobil 194 kendaraan dengan akumulasi tertinggi 33 kendaraan dan rata-rata durasi parkir 108,34 menit/kendaraan. Nilai turn over tertinggi 8,08 dan tingkat penggunaan parkir tertinggi 54,31\%. Jumlah petak parkir yang tersedia saat ini yaitu 33 petak parkir. Sehingga kapasitas ini masih dapat menampung permintaan parkir saat jam puncak sebesar 194 kendaraan yaitu pada pukul 10.00-10.30 WIB.
\end{abstract}

Kata Kunci : karekteristik parkir, pasar larangan

\section{PENDAHULUAN}

Perparkiran bukanlah suatu fenomena yang baru. Perparkiran merupakan masalah yang sering dijumpai dalam sistem transportasi. Di banyak kota baik di kota-kota besar maupun kota-kota yang sedang berkembang selalu menghadapi masalah perparkiran, khususnya untuk kendaraan roda 4. Masalah perparkiran tersebut akhir akhir ini terasa sangat mempengaruhi pergerakan kendaraan, dimana kendaraan yang melewati tempat-tempat yang mempunyai aktivitas tinggi laju pergerakannya akan terhambat oleh kendaraan yang parkir di badan jalan, sehingga hal ini dapat menyebabkan kemacetan. Parkir di pasar Larangan Sidoarjo terbagi atas 2 tempat parkir yaitu parkir pada badan jalan dan parkir di luar badan jalan. Parkir pada badan jalan di pasar Larangan masih semrawut dan kurang teratur, sehingga laju kendaraan yang lewat di sepanjang ruas jalan itu menjadi berkurang, sehingga menyebabkan kemacetan di sepanjang ruas jalan di pasar Larangan. Permasalahan yang perlu diselesaikan adalah bagaimana kinerja parkir (durasi parkir, tangkat pergantian, tingkat penggunaan, volume parkir, kapasitas parkir, indeks parkir, rata-rata durasi parkir, jumlah ruang parkir yang dibutuhkan dapat diketahui hasilnya dan bagaimana rekomendasi. Maksud parkir, tingkat pergantian, tingkat penggunaan, volume parkir, kapasitas parkir, indeks parkir, rata-rata durasi parkir, jumah ruang parkir yang dibutuhkan) di Pasar Larangan Sidoarjo

\section{Parkir}

Pada dasarnya sistem tranportasi terbagi atas 3 elemen utama yaitu kendaraan, prasarana lintasan dan terminal atau pertokoan. Lalu lintas berjalan menuju ke satu tempat tujuan setelah sampainya di tempat tujuan yang akan dibutuhkan adalah tempat pemberhentian. Tempat pemberhentian itu disebut sebagai ruang parkir. Agar sistem tranportasi efisien maka tempat yang ramai adanya aktivitas dan membangkitkan pergerakan perjalanan maka harus menyediakan fasilitas pelayanan yang memadai. Parkir adalah keadaan tidak bergerak dari suatu kendaraan yang bersifat sementara. Pengertian yang lain tentang parkir adalah memberhentikan dan menyimpan kendaraan untuk sementara waktu pada suatu 
ruang tertentu. Kendaraan tidak mungkin bergerak terus, pada suatu saat ia harus berhenti untuk sementara waktu (menurunkan muatan) atau berhenti cukup lama yang disebut parkir (Warpani, 1992).

\section{Satuan Ruang Parkir (SRP)}

Suatu Satuan Ruang Parkir (SRP) adalah tempat parkir untuk satu kendaraan.Pada tempat dimana parkir dikendalikan, maka tempat parkir harus diberi marka pada permukaan jalan. Tempat tambahan diperlukan bagi kendaraan untuk melakukan alih gerak, hal tersebut tergantung dari sudut parkirnya. Penentuan Satuan Ruang Parkir (SRP) dibagi atas tiga jenis kendaraan dan berdasarkan penentuan SRP diklasifikasi menjadi tiga, seperti terlihat pada Tabel 1.

Tabel 1. Penentuan Satuan Ruang Parkir (Perhubungan, 1996)

\begin{tabular}{|c|c|c|}
\hline No & Jenis Kendaraan & $\begin{array}{c}\text { Satuan Ruang } \\
\text { Parkir }\end{array}$ \\
\hline \multirow[t]{3}{*}{1.} & a. Mobil penumpang untuk golongan I & $2.30 \times 5.00$ \\
\hline & b. Mobil penumpang untik golongan II & $2.50 \times 5.00$ \\
\hline & c. Mobil penumpang untuk golongan III & $3.00 \times 5.00$ \\
\hline 2. & Truk/Bus & $3.40 \times 12.50$ \\
\hline 3. & Motor & $0.75 \times 2.00$ \\
\hline
\end{tabular}

Nilai arus lalu lintas (Q) mencerminkan komposisi lalu lintas, dengan menyatakan arus dalam satuan mobil penumpang (smp).Semua nilai arus lalu lintas (per arah dan total) diubah menjadi satuan mobil penumpang (smp) dengan menggunakan ekivalensi mobil penumpang (smp) yang diturunkan secara empiris untuk tipe kendaraan. Ekivalensi mobil penumpang (emp) untuk masingmasing tipe kendaraan tergantung pada tipe jalan dan arus lalu lintas yang dinyatakan dalam kend/jam. Semua nilai emp untuk kendaraan yang berbeda ditunjukan pada Tabel 2 dan Tabel 3.

Tabel 2. Emp untuk Jalan Perkotaan Tidak Terbagi

\begin{tabular}{l|c|c|c|c}
\hline \multirow{2}{*}{$\begin{array}{c}\text { Tipe jalan: Jalan } \\
\text { tak terbagi }\end{array}$} & $\begin{array}{c}\text { Arus lalu lintas total } \\
\text { dua arah (kend/jam) }\end{array}$ & HV & \multicolumn{2}{|c}{$\begin{array}{c}\text { Lempar jalur lalu } \\
\text { lintas WC(m) }\end{array}$} \\
\cline { 3 - 5 } & & & $\leq 6$ & $>6$ \\
\hline Dua-lajur tak & $0 \geq 1800$ & 1,3 & 0,5 & 0,40 \\
terbagi (2/2 UD) & & 1,2 & 0,35 & 0,25 \\
\hline Empat lajur tak & $0 \leq 3700$ & 1,3 & \multicolumn{2}{|c}{0,40} \\
terbagi (4/2 UD) & & 1,2 & \multicolumn{2}{|c}{0,25} \\
\hline
\end{tabular}

Tabel 3. Emp Untuk Jalan Perkotaan Terbagi dan Satu

\begin{tabular}{l|c|c|c} 
& \multicolumn{2}{|c}{ Arah } \\
\hline Tipe jalan: & $\begin{array}{c}\text { Arus lalu lintas } \\
\text { per lajur } \\
\text { Jalan satu arah dan jalan }\end{array}$ & \multicolumn{2}{|c}{ emp } \\
\cline { 3 - 4 } terbagi & $0 \geq 1050$ & 1,3 & 0,40 \\
\cline { 3 - 4 } Dua lajur satu arah (2/1) & & 1,2 & 0,25 \\
danEmpat lajur terbagi & & & \\
(4/2D) & $0 \leq 1100$ & 1,3 & 0,40 \\
\hline Tiga lajur satu arah (3/1) & & 1,2 & 0,25 \\
dan Enam lajur terbagi & & & \\
(6/2D) & & &
\end{tabular}

Kapasitas didefisinisikan sebagai arus maksimum melalui suatu titik di jalan yang dapat dipertahankan per satuan jam pada kondisi tertentu.

Persamaan dasar untuk menentukan kapasitas adalah sebagai berikut:

$$
C=C_{O} \times F C_{W} \times F C_{S P} \times F C_{S F} \times F C_{C S}(\mathrm{smp} / \mathrm{jam})
$$

dengan :

C : kapasitas (smp/jam)

$C_{O} \quad$ : kapasitas dasar (smp/jam)

$F C_{W}$ : faktor penyesuaian lebar jalan

$F C_{S P}$ : faktor penyesuaian pemisah arah (hanya untuk jalan tak terbagi)

$F C_{S F}$ : faktor penyesuaian hambatan samping dan bahu jalan/kereb

$F C_{C S}$ : faktor penyesuaian ukuran kota

\section{METODE PENELITIAN}

Metode penelitian yang dilakukan dapat dilihat pada Gambar 1.

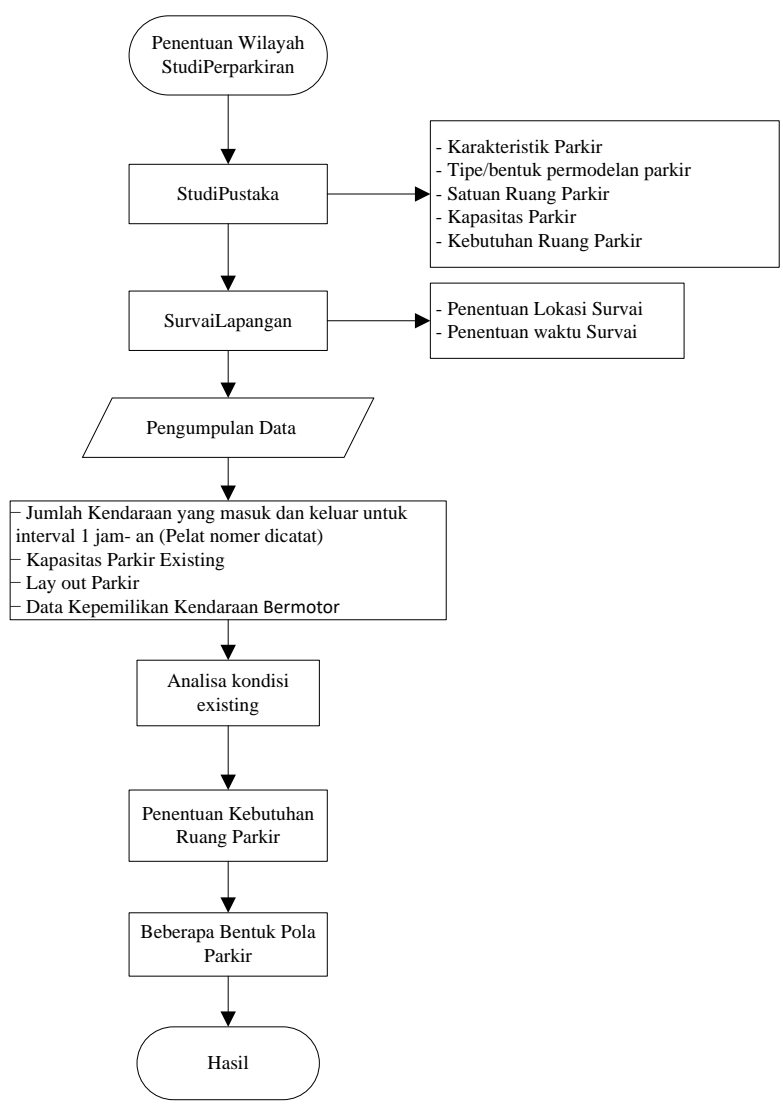

Gambar 1. Diagram alur penelitian

Durasi parkir adalah rentang waktu sebuah kendaraan parkir disuatu tempat (dalam satuan menit atau jam), atau dengan kata lain lamanya parkir sebuah kendaraan ditempat parkir. 


\section{HASIL DAN PEMBAHASAN}

Tabel 4. Durasi Parkir Mobil di Luar Badan Jalan Hari Libur

\begin{tabular}{|c|c|c|c|c|}
\hline No & Plat Kendaraan & Tin & Tout & $\begin{array}{c}\text { Durasi= Tout }- \text { Tin } \\
\text { (Menit) }\end{array}$ \\
\hline 1 & W 1095 ES & 4:00 & 5:08 & 68 \\
\hline 2 & W $1074 \mathrm{FH}$ & 4:02 & 5:49 & 107 \\
\hline 3 & W 1521 DY & $4: 20$ & $5: 50$ & 90 \\
\hline 4 & W 1173 GF & 5:02 & $5: 41$ & 39 \\
\hline 5 & B 8865 JM & 5:08 & 5:52 & 44 \\
\hline 6 & W 2294 VJ & $5: 20$ & $5: 52$ & 32 \\
\hline 7 & W 8029 VG & $5: 20$ & $5: 55$ & 35 \\
\hline 8 & W 7101 BW & $5: 25$ & $5: 59$ & 34 \\
\hline 9 & W 2216 LL & $5: 25$ & $6: 08$ & 43 \\
\hline 10 & W 1652 AN & $5: 26$ & $6: 19$ & 53 \\
\hline 11 & W 1533 DK & $5: 26$ & $6: 26$ & 60 \\
\hline 12 & W 1730 AV & $5: 30$ & $6: 33$ & 63 \\
\hline 13 & W 7373 BP & $5: 32$ & $6: 34$ & 62 \\
\hline 14 & W 2764 KV & $5: 35$ & $6: 50$ & 75 \\
\hline 15 & W 2292 KR & $5: 35$ & 8:06 & 211 \\
\hline 16 & W 1019 ZV & $5: 40$ & 9:09 & 249 \\
\hline 17 & W 1095 DO & $5: 50$ & 7:05 & 195 \\
\hline
\end{tabular}

Grafik Akumulasi Parkir Mobil Di Luar Badan Jalan Pada Hari Libur

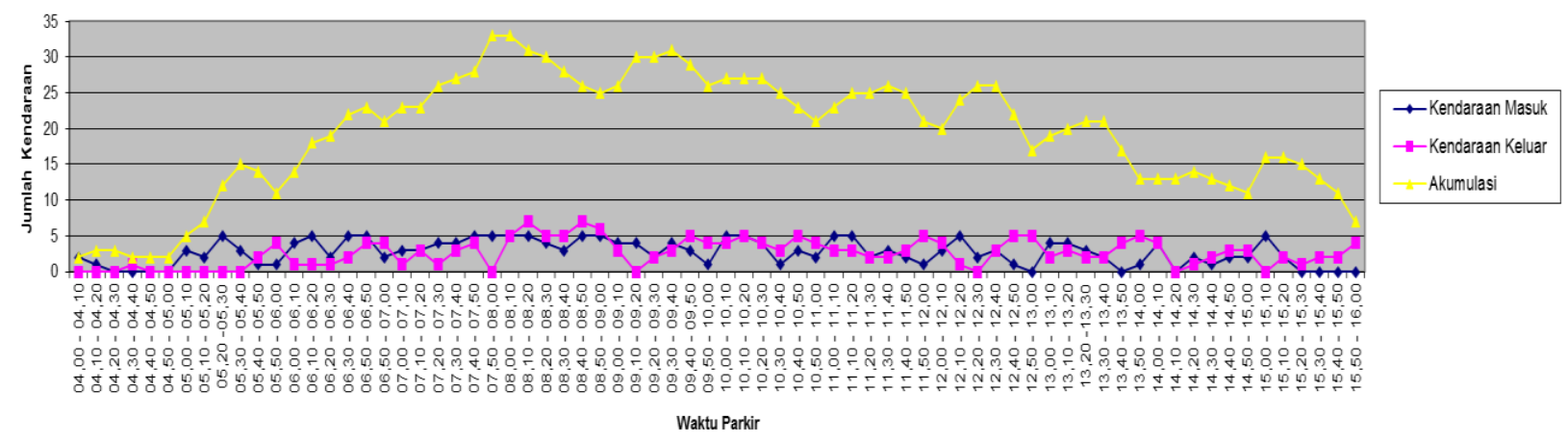

Gambar 2. Grafik Data Arus Kendaraan Mobil Di Luar Badan Jalan Hari Libur

Tabel 5. Klasifikasi Durasi Parkir Mobil di Badan Jalan Hari Libur

\begin{tabular}{|c|c|c|c|c|}
\hline No & $\begin{array}{l}\text { Lama Parkir } \\
\text { (Menit) }\end{array}$ & $\begin{array}{c}\text { Total } \\
\text { Kendaraan }\end{array}$ & $\begin{array}{c}\text { lama parkir } \mathrm{x} \text { total } \\
\text { kendaraan }\end{array}$ & $\begin{array}{l}\text { (lama parkir x total kendaraan) } \\
\text { jumlah total kendaraan }\end{array}$ \\
\hline 1 & 60 & 185 & 11100 & 26,30 \\
\hline 2 & 120 & 191 & 22920 & 54,31 \\
\hline 3 & 180 & 29 & 5220 & 12,37 \\
\hline 4 & 240 & 0 & 0 & 0,00 \\
\hline 5 & 300 & 7 & 2100 & 4,98 \\
\hline 6 & 360 & 1 & 360 & 0,85 \\
\hline 7 & 420 & 5 & 2100 & 4,98 \\
\hline 8 & 480 & 4 & 1920 & 4,55 \\
\hline 9 & 540 & 0 & 0 & 0,00 \\
\hline 10 & 600 & 0 & 0 & 0,00 \\
\hline 11 & 660 & 0 & 0 & 0,00 \\
\hline 12 & 720 & 0 & 0 & 0,00 \\
\hline 13 & 780 & 0 & 0 & 0,00 \\
\hline 14 & 840 & 0 & 0 & 0 \\
\hline 15 & 900 & 0 & 0 & 0 \\
\hline 16 & 960 & 0 & 0 & 0 \\
\hline \multirow[t]{2}{*}{17} & 1020 & 0 & 0 & 0 \\
\hline & Jumlah & 422 & 45720 & 108,34 \\
\hline
\end{tabular}




\section{Grafik Durasi Parkir Mobil Badan Jalan Hari Libur}

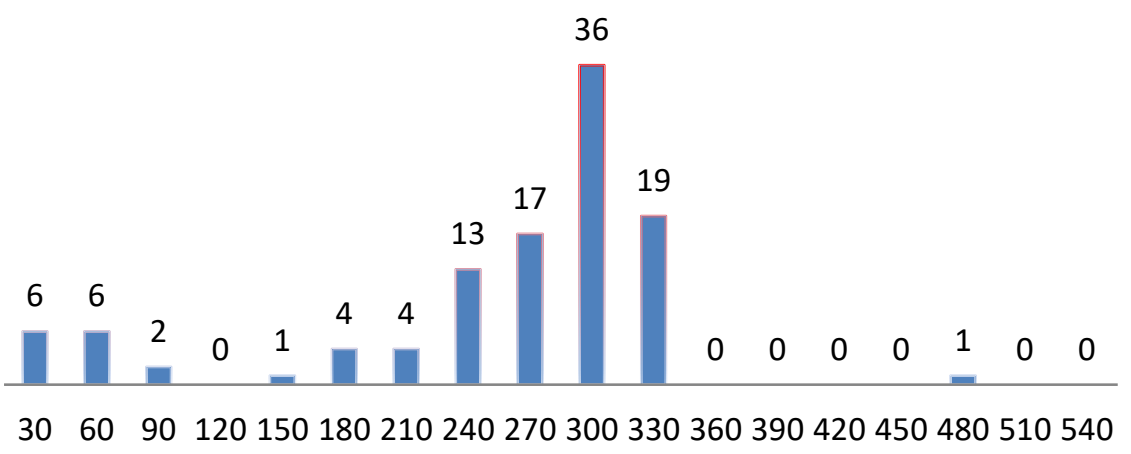

Gambar 3. Grafik Klasifikasi Durasi Parkir Mobil Di Badan Jalan di Hari Libur

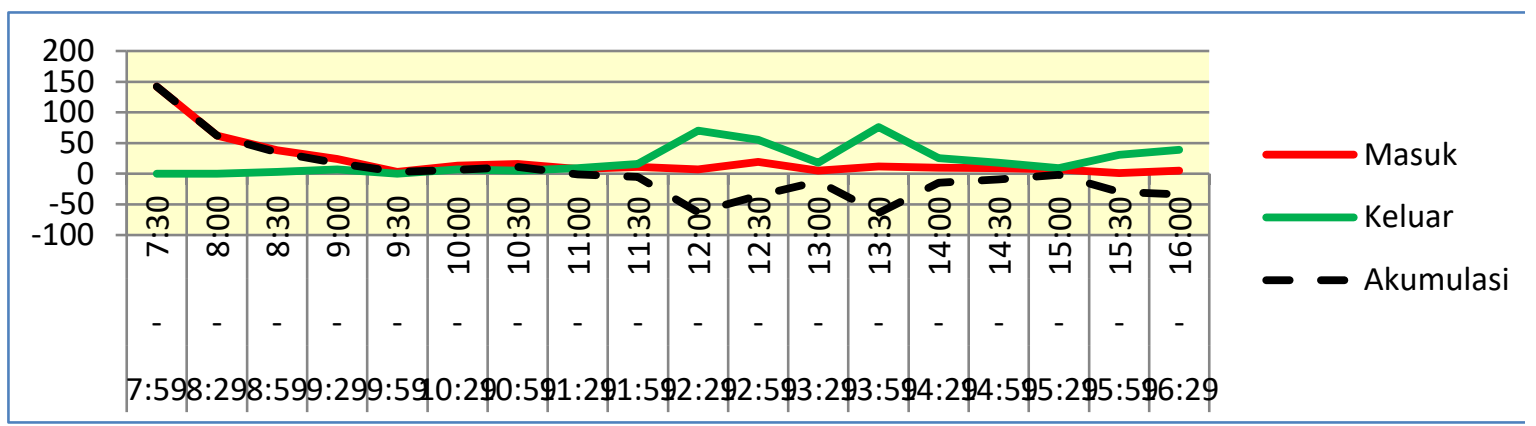

Gambar 4. Grafik Akumulasi Sepeda Motor Badan Jalan Hari Libur

Dari data Tabel 5 dapat dilihat pada Grafik Gambar 3. berdasarkan klasifikasi durasi parker Mobil Badan Jalan Hari Libur pada kendaraan mobil adalah sama dengan atau kurang dari 300 menit atau 5 jam sebanyak 36 unit. Dan yang terendah pada adalah 150 menit dan 480 menit sebanyak 1 unit.

Akumulasi parkir adalah jumlah kendaraan yang sedang berada di suatu lahan parkir pada selang waktu tertentu, dan dapat dibagi sesuai dengan kategori jenis maksud perjalanan.

Tabel 6. Akumulasi Parkir Sepeda Motor Di Badan Jalan Hari Libur

\begin{tabular}{c|c|c|c|c|c|c|c}
\hline No & \multicolumn{2}{|c|}{ Waktu } & Ei & Ex & Akumulasi = Ei-Ex & Kumu latif \\
\hline 1 & $7: 30$ & - & $7: 59$ & 143 & - & 143 & 143 \\
\hline 2 & $8: 00$ & - & $8: 29$ & 62 & - & 62 & 204 \\
\hline 3 & $8: 30$ & - & $8: 59$ & 38 & 3 & 35 & 239 \\
\hline 4 & $9: 00$ & - & $9: 29$ & 24 & 7 & 17 & 256 \\
\hline 5 & $9: 30$ & - & $9: 59$ & 3 & - & 3 & 259 \\
\hline 6 & $10: 00$ & - & $10: 29$ & 13 & 7 & 6 & 265 \\
\hline 7 & $10: 30$ & - & $10: 59$ & 16 & 5 & 11 & 276 \\
\hline 8 & $11: 00$ & - & $11: 29$ & 8 & 9 & -1 & 275 \\
\hline 9 & $11: 30$ & - & $11: 59$ & 11 & 16 & -5 & 270 \\
\hline 10 & $12: 00$ & - & $12: 29$ & 7 & 70 & -63 & 207 \\
\hline 11 & $12: 30$ & - & $12: 59$ & 19 & 55 & -36 & 171 \\
\hline 12 & $13: 00$ & - & $13: 29$ & 5 & 18 & -13 & 158 \\
\hline 13 & $13: 30$ & - & $13: 59$ & 12 & 76 & -64 & 94 \\
\hline 14 & $14: 00$ & - & $14: 29$ & 10 & 25 & -15 & 79 \\
\hline 15 & $14: 30$ & $-14: 59$ & 9 & 18 & -9 & 70 \\
\hline 16 & $15: 00$ & - & $15: 29$ & 7 & 9 & -2 & 68 \\
\hline 17 & $15: 30$ & - & $15: 59$ & 1 & 31 & -30 & 38 \\
\hline 18 & $16: 00$ & $-16: 29$ & 5 & 39 & -34 & 4 \\
\hline \multicolumn{7}{|c|}{ Sumber: Hasil Analisis }
\end{tabular}

Sumber: Hasil Analisis
Dari data Tabel 6 dan grafik pada Gambar 4 dapat dilihat tingkat selisih tertinggi dan terendah nilai akumulasi kendaraan sepeda motor pada jam $7.30 \mathrm{~s} / \mathrm{d} 7.59 \mathrm{Wib}$ yang masuk 142 unit dan yang keluar 0 unit maka nilai akumulasinya adalah 142 unit dan pada pukul $13.30 \mathrm{~s} / \mathrm{d} 13.59 \mathrm{Wib}$ yang masuk 12 unit dan yang keluar 76 unit maka nilai akumulasinya adalah-64 unit (kurang dari enam puluh empat unit).

\section{PENUTUP}

Hasil analisis diperoleh bahwa karakteristik parkir sepeda motor dengan volume parkir di badan jalan pada hari libur sebesar 1.104 kendaraan dengan akumulasi tertinggi 133 kendaraan dan rata-rata durasi parkir 128,52 menit/kendaraan. Nilai turn over tertinggi 7,63 dan tingkat penggunaan parkir tertinggi 190,34 \%. Jumlah petak parkir yang tersedia saat ini yaitu 150 petak parkir sehingga kapasitas ini tidak bisa menampung permintaan parkir saat jam puncak sebesar 270 kendaraan pada pukul 10.00-10.59. Nilai indeks parkir sepeda motor di pasar Larangan saat ini masih kurang memadahi. Sedangkan karakteristik parkir mobil dengan volume parkir mobil 194 kendaraan dengan akumulasi tertinggi 33 kendaraan dan rata-rata durasi parkir 108,34 menit/kendaraan pada hari libur. Nilai turn over tertinggi 8,08 dan tingkat penggunaan parkir tertinggi 54,31 \%. Jumlah petak parkir yang 
tersedia saat ini 33 petak parkir sehingga kapasitas ini masih dapat menampung permintaan parkir saat jam puncak sebesar 194 kendaraan yaitu pada pukul 10.00-10.30. Nilai indeks parkir mobil di Pasar Larangan untuk saat ini masih kurang. Jumlah kekurangan petak parkir tertinggi untuk sepeda motor yaitu 120 petak parkir dan mobil untuk mobil 10 petak parkir.

Untuk rekomendasi yang dapat diberikan kepihak Unit parker Pasar Larangan sebaiknya mulai menyiapkan lahan/tempat parker baru guna menutupi kekurangan (SRP) Satuan Ruang Parkir disaat jam puncak. Unit Pasar Larangan Sidoarjo, agar senantiasa mengantisipasi kenaikan jumlah sepeda motor dan mobil untuk masa akan datang. Apabila perkembangan jumlah kendaraan tidak diantisipasi, dikhawatirkan pelayanan terhadap masyarakat atau pengunjung akan kurang maksimal.

\section{DAFTAR PUSTAKA}

Arishandi, N. G., Suthanaya, P. A., \& Wedagama, D. M. P. (2017). ANALISIS KARAKTERISTIK DAN KEBUTUHAN PARKIR TERMINAL KARGO DI KOTA DENPASAR. Jurnal Spektran.

https://doi.org/10.24843/SPEKTRAN.2017. v05.i01.p09

BUDHI W, A., \& FERNANDA S, T. (2006). ANALISA KEBUTUHAN RUANG PARKIR JAVA SUPERMALL SEMARANG.

Gea, M. (2013). Analisis Kinerja Ruas Jalan Akibat Parkir Pada Badan Jalan (Studi Kasus: Pasar dan Pertokoan di Jalan Besar Delitua). Jurnal Teknik Sipil USU, 1(2).

HANDAYANI, Y. S. R. I., Suwandono, D., \& Manulang, O. R. (2002). ANALISIS KARAKTERISTIK PARKIR KHUSUS TERHADAP INTENSITAS PARKIR DI KAWASAN SIMPANG LIMA. Universitas Diponegoro.

Jaya Wikrama, A. A. (2010). Analisis Karakteristik dan Kebutuhan Parkir di Pasar Kreneng. Jurnal Ilmiah Teknik Sipil, 14(2).

Kasan, M. (2010). Model Kebutuhan Satuan Ruang Parkir Usaha Perdagangan Pakaian di Kota Palu. SMARTek, 8(1).

Limantara, A. D., Candra, A. I., \& Mudjanarko, S. W. (2017). MANAJEMEN DATA LALU LINTAS KENDARAAN BERBASIS SISTEM INTERNET CERDAS UJICOBA IMPLEMENTASI DI LABORATORIUM UNIVERSITAS KADIRI. Prosiding Semnastek.
Limantara, A. D., Purnomo, Y. C. S., \& Mudjanarko, S. W. (2017). PEMODELAN SISTEM PELACAKAN LOT PARKIR KOSONG BERBASIS SENSOR ULTRASONIC DAN INTERNET OF THINGS (IOT) PADA LAHAN PARKIR DILUAR JALAN. Prosiding Semnastek.

Mudjanarko, S. W., \& Sulistio, H. (2013). Behaviour Model of Motor Cycle User in Selecting Parking Location (Case study in Surabaya City of Indonesia). Journal of Basic and Applied Scientific Research (JBASR), 3, 842846.

Perhubungan, D. (1996). Keputusan Direktur Jendral perhubungan Darat Tentang Pedoman Teknis Penyelenggaraan Fasilitas Parkir. Jakarta.

Purbanto, I., \& Raka, G. (2012). Karakteristik Parkir Pinggir Jalan (On Street Parking) dan Pengaruhnya Terhadap Kinerja Ruas Jalan. Jurnal Ilmiah Teknik Sipil. Vol, 16.

Sudirahardjo, R. (2003). Analisis Kebutuhan Ruang Parkir Di Pasar Bandarjo Ungaran. Magister Teknik Sipil.

Sulistio, H., \& Mudjanarko, S. W. (2011). SCENARIO OF PARKING DISTRIBUTION WITH INTELLIGENT TRANSPORTATION SYSTEMS. International Journal of Academic Research, $3(2)$.

Supriono, J., \& Mudjanarko, S. W. (2016). Evaluasi Kinerja Parkir Di Rsu Haji Surabaya. E-Jurnal Spirit Pro Patria, 1(2).

Suthanaya, P. A. (2010). Analisis Karakteristik Dan Kebutuhan Ruang Parkir Pada Pusat Perbelanjaan Di Kabupaten Badung. Jurnal Ilmiah Teknik Sipil, 14(1).

Suwardi, S. (2009). ANALISIS KARAKTERISTIK DAN DAMPAK PARKIR TERHADAP LALULINTAS, DI SOLO GRAND MALL SURAKARTA. Jurnal Teknik Sipil Universitas Atma Jaya Yogyakarta, 8(2), pp-105.

Warpani, S. (1992). Kependudukan dan Pembangunan Daerah di Indonesia. Journal of Regional and City Planning, 3(3), 10-15.

Yulmida, D., Mudjanarko, S. W., Setiawan, M. I., \& Limantara, A. D. (2017). Analisis Kinerja Parkir Sepanjang Jalan Walikota Mustajab Surabaya. U KARST, 1(1). 
R Sholikhin, dkk / Teknika : Engineering and Sains Journal, Vol. 1, No.2, Desember 2017, 145-150

Halaman ini sengaja dikosongkan 